\title{
ANALISIS PORTOFOLIO SAHAM LQ45 MENGGUNAKAN FUNGSI UTILITAS KUADRATIK
}

\author{
KAdek Frisca Ayu Devi ${ }^{1}$, Komang DharmaWan ${ }^{2}$, Ni MAde ASIH ${ }^{3}$ \\ 1, 2,3 Jurusan Matematika FMIPA Universitas Udayana, Bukit Jimbaran-Bali, \\ e-mail: ${ }^{1}$ frisca_devi@yahoo.co.id \\ 22dharmawan.komang@gmail.com, ${ }^{3}$ sedhana2@gmail.com
}

\begin{abstract}
Utility function can use to give risk preference for investors who want to get the benefits gained meets investment targets. Quadratic utility functions on optimal portfolio is strongly influenced by the expected return and standard deviation. The establishment of optimal portfolios using a quadratic utility function optimization problems. Under the settlement portfolio optimization, the necessary data is expected return, variance, and variance covariance matrix. The optimal portfolio is affected by some factors Risky less Rate, risk aversion index, and Borrow Rate. The results of settlement portfolio optimization is obtaining the utility value while the relatively large changes influencing by risk averse index.
\end{abstract}

Keywords: Portofolio optimal, Historical data, utility function

\section{Pendahuluan}

Portofolio optimal merupakan porofolio yang dipilih seorang investor dari sekian banyak pilihan yang ada pada kumpulan portofolio yang efesien [4]. Dengan adanya perilaku risk aversion menjadi obyek ketertarikan penulis untuk mendapatkan tingkat keengganan terhadap risiko (risk aversion). Persamaan yang digunakan untuk mewakili keenganan terhadap risiko adalah Fungsi Utilitas untuk mendapatkan tingkat keengganan terhadap risiko (risk aversion). Dengan menggunakan Fungsi Utilitas ini juga merupakan salah satu cara yang digunakan oleh para investor dalam membentuk sebuah portofolio. Fungsi utilitas digunakan, karena mampu memberikan preferensi risiko bagi investor yang menginginkan agar keuntungan yang didapatkan telah memnuhi target investasi.

\section{Metode Penelitian}

Langkah-langkah penelian ini adalah: (1) Membentuk expected return dan membentuk varians portofolio; (2) Menentukan proporsi dana yang mungkin dari masing-masing saham; (3) Membentuk beberapa risiko dan return portofolio yang efesien dari beberapa proporsi dana yang memungkinkan; (4) Membentuk Capital Allocation Line (CAL). Dari sekumpulan portofolio yang efesien maka dapat dibentuk portofolio optimal dengan bantuan Capital Allocation Line (CAL); (5)

\footnotetext{
1 Alumni Mahasiswa Jurusan Matematika FMIPA Universitas Udayana

${ }^{2,3}$ Staf Pengajar Jurusan Matematika FMIPA Universitas Udayana
} 
Dari Capital Allocation Line (CAL) dan sekumpulan portofolio yang efesien maka dapat dibentuk kurva efficient frontier; (6) Menentukan portofolio optimal melalui efficient frontier. Sehingga didapat nilai risiko portofolio dan return portofolionya; (7) Nilai risiko dan return portofolio dapat digunakan untuk menentukan nilai utilitas kuadratik

\section{Hasil dan Pembahasan}

Data saham dari data historis dicari nilai harapan pengembalian (expected return) dan standar deviasi masing-masing saham. Harapan pengembalian (expected return) dapat dihitung dengan rumus:

$$
E(R)=\frac{1}{n} \sum_{t=1}^{n} r_{t}
$$

Rt dapat dihitung dengan formula :

$$
r_{\mathrm{t}}=\ln \left(\frac{s_{\mathrm{t}}}{s_{\mathrm{t}-1}}\right) \text {, untuk } t=1,2, \ldots, n
$$

Dimana $S_{t}$ adalah harga aset pada saat $t$ dan $n$ jumlah periode data pergerakan harga saham.

Variansi dari tingkat pengembalian (return) sebuah saham dengan sejumlah $n$ buah data dirumuskan sebagai berikut:

$$
\sigma^{2}=\frac{1}{n} \sum_{t=1}^{n}\left(r_{t}-E(R)\right)^{2}
$$

Standar deviasi dari saham sebagai berikut :

$$
\sigma=\sqrt{\sigma^{2}}
$$

dimana $\sigma^{2}$ merupakan nilai variansi dari tingkat pengembalian suatu aset, $R_{t}$ menyatakan tingkat pengembalian (return) dari suatu aset pada saat $\mathrm{t}$ dan $\sigma$ menyatakan nilai standar deviasi suatu aset.

Tabel 1. Hasil Expected Return, Variansi dan Standar Devasinya

\begin{tabular}{|l|c|c|c|}
\hline Saham & $\mathbf{E}(\mathbf{r})$ & varians & Standar deviasi \\
\hline Astra Agro Lestari Tbk (AALI) & 0.0145 & 0.0063 & 0.0791 \\
\hline Bank Central Asia Tbk (BBCA) & 0.0243 & 0.0063 & 0.0794 \\
\hline Indofood Sukses Makmur Tbk (INDF) & 0.0395 & 0.0103 & 0.1016 \\
\hline Indosat Tbk (ISAT) & 0.0029 & 0.0101 & 0.1005 \\
\hline
\end{tabular}

Sehingga dapat dibentuk koefesien korelasi dan varians kofarians masingmasing saham:

Tabel 2. Koefisien Korelasi

\begin{tabular}{|c|c|c|c|c|}
\hline Saham & ALI & BCA & NDF & SAT \\
\hline ALI & & .3328 & .3688 & .1895 \\
\hline BCA & .3328 & & .4852 & .6498 \\
\hline NDF & .3688 & .4852 & & .4005 \\
\hline SAT & .1895 & .6498 & .4005 & \\
\hline
\end{tabular}

Tabel 3. Varians Kovarian

\begin{tabular}{|c|c|c|c|c|}
\hline Saham & ALI & BCA & NDF & SAT \\
\hline ALI & .0063 & .0021 & .003 & .0015 \\
\hline BCA & .0021 & .0063 & .0039 & .0052 \\
\hline NDF & .003 & .0039 & .0063 & .0041 \\
\hline SAT & .0015 & .0052 & .0041 & .0063 \\
\hline
\end{tabular}


Hasil optimasi portofolio, data yang diperlukan expected return, variansi, matriks varians kovarian. Dengan mengasumsikan RisklessRate sebesar sebesar 0,5\%, tingkat risk aversion sebesar 4, dan BorrowRate sebesar 0,7\%.

Gambar 1. Hasil keluaran Matlab

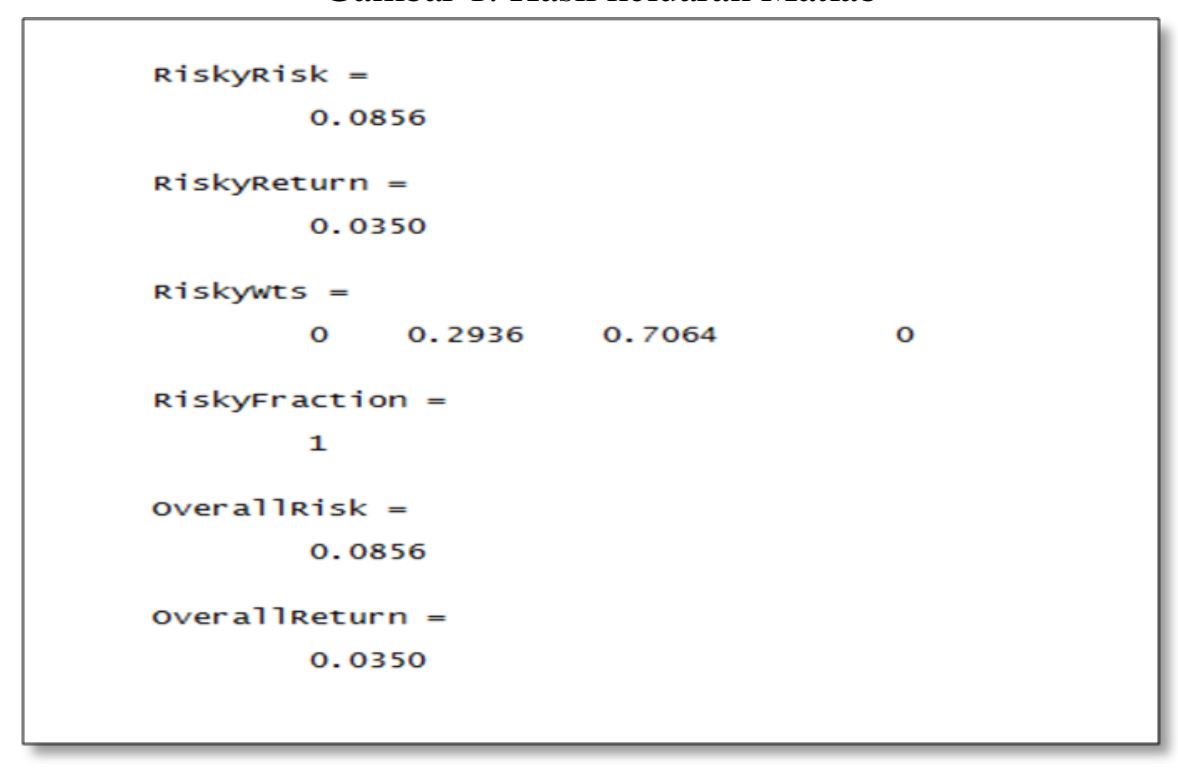

Hal ini menunjukkan bahwa investor mentolerir adanya RiskFraction sebesar $100 \%$. Keuntungan portofolio secara keseluruhan (OverallReturn) sebesar 3,5\% dan standar deviasi secara keseluruhan sebesar (OverallRisk) sebesar 8,56\%. Proporsi dana yang optimal dari masing-masing saham adalah $w_{1}=0, w_{2}=$ $0,2936, w_{3}=0,7064, w_{4}=0$.

Gambar 2. Efficient Frontier

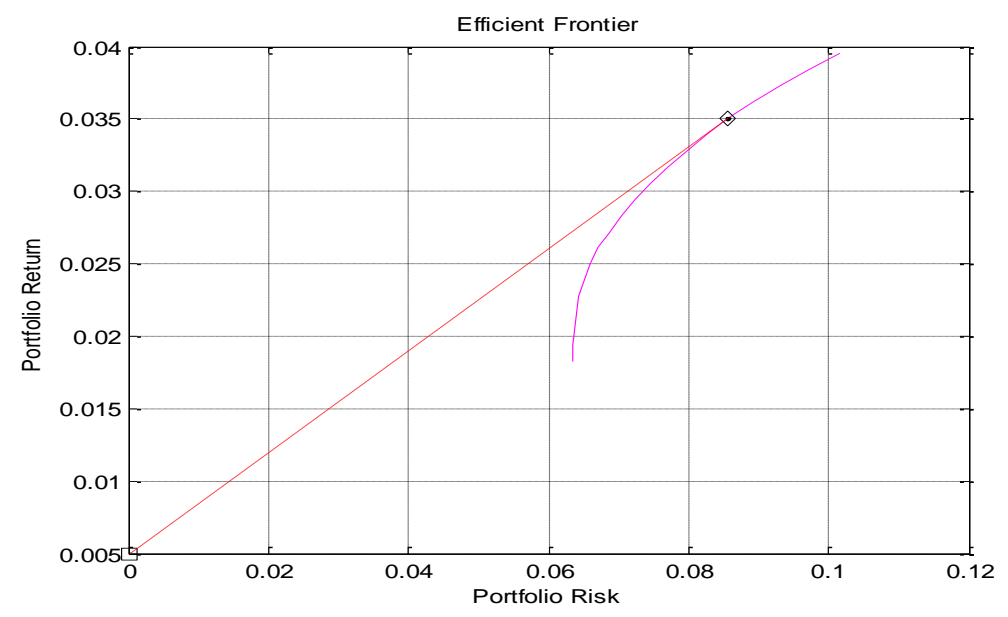

garis yang membentuk concave merupakan serangkaian titik yang akan membentuk garis yang merupakan efficient frontier yang terdiri dari serangkaian portofolio yang efisien. Portofolio yang efisien adalah portofolio yang memberikan tingkat keuntungan yang terbesar dengan risiko yang sama atau risiko terkecil dengan tingkat keuntungan yang sama. Garis efficient frontier yang menyinggung CAL (Capital Allocation Line) di satu titik merupakan titik yang membentuk portofolio yang optimal. 
Didapatkan nilai portofolio yang optimal sehingga diperoleh nilai utilitas. Dimana nilai OverallReturn merupakan harapan keuntungan (expected return) portofolio dan OverallRisk merupakan standar deviasi portofolio. Dan nilai indeks yang digunakan kisaran 2 hingga 4 . Berikut akan disajikan nilai utilitas :

$$
\begin{aligned}
\mathrm{U} & =E\left(r_{p}\right)-0.005 \mathrm{~A} \sigma_{p}^{2} \\
& =0.0350-0.005 .4 .0,0856 \\
=0.0333 &
\end{aligned}
$$

Hal ini menunjukan tingkat keenganan risiko terhadap keempat saham sebesar $3.33 \%$.

\section{Kesimpulan}

Dengan menggunakan fungsi utilitas kuadratik pada pengelolaan portofolio optimal sangat dipengarhi oleh expected return dan standar deviasi. Hal ini menyatakan bahwa utilitas dari kenaikan portofolio akan meningkat dan akan menurun jika variansnya meningkat. Perubahan yang relatif besar dipengaruhi oleh indeks risk averse.

Portofolio optimal yang didapat menunjukan bahwa faktor yang mempengaruhi portofolio optimal adalah keuntungan investasi bebas resiko, indeks risk aversion, dan suku bunga pinjaman.

\section{Daftar Pustaka}

[1] Husnan S. 1998. Dasar-dasar Teori Portofolio dan Analisis Sekuritas : Edisi Ketiga. UPP AMP YKPN. Yogyakarta.

[2] Yogianto. 2003. Analisis Investasi dan Teori Portofolio. Gajah Mada Press, Yogyakarta.

[3] Luenberger, D.G. 1998. Investment Science. Stanford Univercity. New York.

[4] Tandellin, Eduardus. 2001. Analisis Kinerja Portofolio Saham dengan Metode Sharpe, Treynor dan Jensen (Saham LQ45 di Bursa Efek Indonesia Tahun 2003 sampai 2007). Program Studi Magister Manajemen Universitas Diponegoro. 